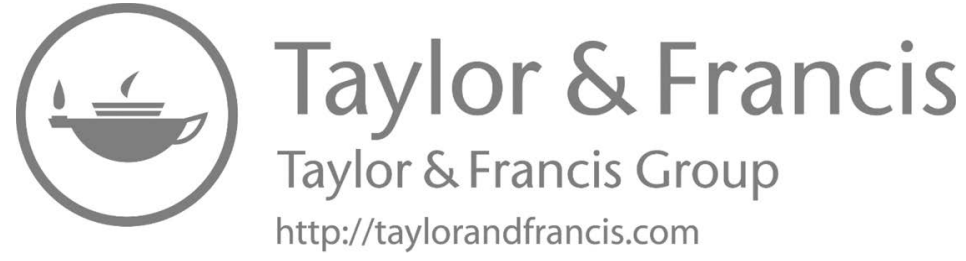




\title{
20
}

\section{GRAPPLING WITH THE PANDEMIC}

\section{Rich insights into intergovernmental relations}

\author{
Cheryl Saunders
}

\subsection{Introduction}

The purpose of this chapter is to examine the theory and practice of intergovernmental relations in the light of the experiences of federations in dealing with Covid-19. To this end, this chapter draws on the information provided by 18 country case studies in this book, together with a study of the European Union. All cases have federal or quasi-federal systems of government. Otherwise, however, they are diverse in a wide variety of ways that include geographic and population size and configuration, economic development, political system, and the framework for federalism itself. Factors of these kinds influenced the ways in which each of these federations has responded to the pandemic, including, relevantly for this chapter, the role of intergovernmental relations.

All the case studies were finalised towards the end of 2020, with the result that neither they nor this chapter take account of subsequent developments in intergovernmental relations as the pandemic continued to play out. As they stand, the cases are a rich resource yielding new knowledge and understanding of intergovernmental relations in federal systems in a context in which governmental systems have been placed under extreme and unusual stress. The time limitation is relevant, nevertheless. As these chapters show, intergovernmental relations changed within federations in the course of 2020 in tandem with successive 'waves' of the pandemic and policy responses to it. That evolution can be expected to have continued into 2021, when governments were still struggling to manage the pandemic and vaccines began to be rolled out.

The challenges presented by the spread of the Covid-19 across the world were a test of federal systems generally and intergovernmental relations in particular. The pandemic created two types of crises, one with serious implications for 
public health and the other affecting national and subnational economies. These two sets of issues were typically seen as in competition with each other, albeit on the understanding that if the health crisis were managed quickly and effectively, they could be reconciled. How the tension between the two played out in any federation depended on a mixture of ideological preferences, the federal division of powers, and the realities on the ground. In every case, however, these complex, interlinked crises, affecting the lives of communities in so many respects, required an exercise of authority by all levels of government. Each level of government had a role of some kind to play, even where formal emergency powers were invoked. Failure was all too obvious, placing a premium on capability and performance. More often than not, an effective response required coordination across jurisdictional lines, both horizontal and vertical, in ways that also preserved the potential for localised divergence.

In the analysis that follows, intergovernmental relations are understood broadly as covering all instances in which governments in a federal systems work together across jurisdictional boundaries in the common interest. The term thus refers to activity that, strictly speaking, might be described as intragovernmental inasmuch as an institution of one level of government is constituted to incorporate representatives of another: the German Bundesrat, comprising representatives of Land governments, is an example. The term also includes relations between governments that, from the standpoint of the formal constitutional scheme, are constitutionally or legally mandated, as well as those in which joint action is voluntary. In addition, it includes situations in which joint action is top-down and in effect coercive rather than 'cooperative', to invoke another term often used in this context.

A broad and inclusive understanding of the subject is necessitated by the variety of approaches to intergovernmental relations in this range of federal-type systems, approaches which are manifested not only in the practices that are adopted but in the ways in which intergovernmental relations are conceived and described. A narrower approach would risk a partial understanding of how governments interacted with each other in responding to Covid-19. Conversely, it may be, as I will argue, that analysis of the range of responses to Covid-19 enables a more nuanced, critical appraisal of intergovernmental relations which identifies practices that are more productive than others without necessarily excluding any from the field.

The rest of this chapter proceeds as follows. To aid comparison, the next section identifies and explains aspects of each federal-type system that have a bearing on intergovernmental relations. section 3 considers the purposes for which intergovernmental relations were used by different federal-type systems in responding to the pandemic, while section 4 examines the modalities through which intergovernmental relations took place. The final section highlights the most significant insights gleaned from the experience of Covid-19 and serves to inform future research in the field. 


\subsection{Contexts}

The contexts in which federal-type systems operate differ in many ways that are relevant to an assessment of intergovernmental relations in response to Covid-19. This section draws attention to four of the most significant forms of differentiation: geophysical characteristics, economic development, the form and operation of government, and the multifaceted framework for federalism itself. Each of these aspects of context is significant in its own right; they also combine in different ways in different federations to create distinctive settings that need to be understood before general conclusions are drawn.

For present purposes, geophysical characteristics include the geographical size of a country, its distribution into federated units, patterns of population settlement, particularly around internal borders, and global location. The range can be grasped by comparing, for example, Switzerland and Austria with Canada and Australia. The former both have a relatively small land mass, divided into 26 cantons (Switzerland) and nine Länder (Austria). They have a population density of 219 and 109 persons per kilometre, respectively, and external land borders shared with other densely populated countries on all sides. Both Canada and Australia, by contrast, have a large land mass divided into 13 provinces and territories (Canada) and eight states and territories (Australia) and a population density of 4 and 3 persons per $\mathrm{km}^{2}$, respectively. They are located far from the huge, interconnected Eurasian continent.

In geographically smaller federations like these, conditions relevant to managing the pandemic are less likely to vary significantly between units, while internal borders are likely to be porous, strengthening the case for harmonisation of policy settings and for cross-border cooperation. In geographically larger federations, however, the rate of infection and other conditions pertinent to the pandemic are more likely to vary between units, suggesting that intergovernmental arrangements should leave greater room for policy divergence around the country and increasing the importance of gathering information from localised sources. It may also be noted in passing that a larger number of units creates a different dynamic for multilateral intergovernmental relations than a smaller one, and may also have a bearing on the size and capabilities of individual units.

A second aspect of context is economic development. Less affluent countries have fewer options at their disposal to respond to the pandemic. Health systems are likely to be weaker and more readily overrun; resources are less likely to be available to support the isolation of those exposed to infection; supplies, including vaccines, may be hard and slow to obtain. These realities channel the policy choices available to governments individually or collectively. It may also be that, in circumstances of slow or recent economic development, all levels of government but, in particular, subnational levels, lack the capacity, in the sense of capability, to respond to the challenges of Covid-19 effectively. South Africa is a case in point, where the authors identify 'incapacity, incompetence and corruption' on the part of provinces and municipalities; problems that certainly also are 
experienced in federations elsewhere. The likelihood that the centre will dominate the Covid-19 response may be heightened in such cases by the federation's design, which typically concentrates power at the centre and provides authority for central intervention in unit affairs when major problems arise.

Thirdly, the form of government influences intergovernmental relations in ways that were relevant to responses to the pandemic. Most obviously, the distinction between parliamentary and presidential systems affected some modalities of intergovernmental relations in relation to Covid-19. Governments in parliamentary systems are more likely than those in presidential systems to use formal meetings of heads of government for the purposes of vertical coordination, if only because agreement between governments can lead easily enough to legislative action. Most of the parliamentary federations covered by the case studies used meetings of some kind between heads of government of the federation and federated units to coordinate aspects of their responses to the pandemic, although the frequency and significance of these meetings varied. By contrast, none of the six presidential systems (Mexico, Brazil, Argentina, Nigeria, Russia, United States (US)) recorded systematic vertical meetings between heads of government, although horizontal meetings between the governments of some or all units were common and informal, often bilateral, contacts between the president and governors sometimes took place.

More authoritarian styles of government also affected intergovernmental relations during the pandemic, doing so in the adoption of approaches that were top-down, less likely to be consultative, and more likely to mandate action of specified kinds by the federated units. Russia is an example where, nevertheless, the sheer size of the country ultimately required some local diversity as it responded to the pandemic. A tendency towards top-down central action also was present in other federations in which a single party is dominant across all levels of government. The syndrome is evident across both presidential and parliamentary systems, as the examples of Argentina, Mexico, Ethiopia, Nigeria, and South Africa show, although it manifests somewhat differently in each case.

The cases show that the distribution and strength of party-political allegiances affected the intergovernmental response to the pandemic in other ways as well. Generally speaking, parties broadly on the right were inclined to prioritise the economy and eschew restrictions on individual movement for infection control, while those broadly on the left were more likely to prioritise public health. The mix of parties in office in the various jurisdictions, combined with the distribution of federal powers and responsibilities, thus helped to shape the outcomes of intergovernmental negotiations.

For example, in Australia, operating through a newly established 'National Cabinet', the particular admixture of interests and power had the effect of softening extreme positions, leading to intergovernmental US, deep compromises that proved effective in minimising transmission. By contrast, in the ideological differences, both horizontal and vertical, served to deter effective intergovernmental arrangements altogether. Predictably, too, across a range of federations party 
allegiances variously resulted in favouritism towards particular units, notwithstanding formal intergovernmental arrangements; encouraged alliances between some units to the exclusion of others; and offered an alternative avenue to intergovernmental relations. Equally, however, the significance of party affiliation should not be overstated. The exigencies of responding to the pandemic were experienced by all jurisdictions in all federations and were capable of creating common cause across party lines, at least until the worst of the crisis had passed.

The federal distribution of powers or competences is another contextual factor that affected the form and operation of intergovernmental relations. It has at least three dimensions that are relevant for present purposes: the contrast between dual and integrated federations, the categorisation of legislative powers, and the distribution of the powers and competences on which responses to the pandemic drew.

The categories of dual and integrated federations refer, respectively, to federations in which each jurisdiction administers its own legislation and those in which subnational governments can, or must, implement some central legislation. During the pandemic, intergovernmental relations in federations with features of integration often took the form of policy-making through central legislation that was implemented by other levels of government - an option which typically is not available to federations with a dualist design. The US is an example of a country in which integration is precluded, or at least restricted by a decision of the Supreme Court invalidating the 'commandeering' of State officials by federal law (Printz v. United States (1997) 521 US 898 (1997)). Australia may be another.

However, there also are variations within each of these two models that affected intergovernmental relations. Some integrated federations, including Germany, have formal procedures for consultation with federated units about the laws they are to implement. Others, of which Germany also is an example, allow substantial discretionary scope to federated units in the course of implementation. Some dualist federations, of which Canada is an example, do not constitutionally preclude implementation of central law by the federated units, or vice versa, if agreed between jurisdictions, although the device was not used in responding to the pandemic.

A second dimension of the federal division of powers that contributes to contextual differences that could affect intergovernmental relations is the categorisation of allocated powers. One familiar point of distinction lies between concurrent and exclusive powers; less familiar are differences in the understanding of concurrency in different systems, differences that can also come into play in intergovernmental relations (Saunders and Dziedzic 2017). As a generalisation, there is a dividing line between federations in which concurrency is understood as involving joint action of some kind and those in which it merely involves identifying legislative powers which are potentially available for exercise by either level of government, subject to a rule about which law prevails if both seek to exercise the power. This difference in understanding may be attributable in part to the role played by concurrent power in the overall allocation of power. In some federations, of which Australia is an example, concurrency is used to 
categorise in a single list most of the powers available to the central legislature, without there necessarily being any implication of joint action. In other federations, including, for example, India and South Africa, concurrent power complements two other lists of exclusive powers by identifying powers that are shared.

Whatever the explanation, different understandings of concurrency emerge from comparative analysis of intergovernmental relations in federations during the pandemic. In some cases, of which Mexico, South Africa, and Italy are examples, concurrent power enabled the centre to provide a legal framework, of varying degrees of detail, within which federated units supplemented and administered the central legislation. In other cases, of which Australia is an example, both levels of government enacted and administered their own legislation by relying on aspects of the same concurrent power and taking legislative precautions against invalidation for unintended inconsistency. ${ }^{1}$

In many cases, this familiar format for the structure of the federal division of power was modified or embellished, sometimes in distinctive ways. So, for example, Mexico distinguishes 'coordination' from concurrency; ${ }^{2}$ Argentina distinguishes 'shared' from concurrent power, describing the former as requiring 'joint decisions'; Brazil provides separately for 'concurrent' legislative powers and administrative powers that are held 'in common' (Brazil, Constitution, articles 23 and 24); Italy subjects 'shared' powers to principles prescribed in national legislation; and Austria specifically provides for the enactment of 'framework' legislation by the Bund, leaving 'more detailed implementation' to Land legislation (Austria, Constitution, article 15(6)). Some federations, including Belgium, rely entirely on exclusive powers and do not use concurrency at all. Notably, however, in Canada, where most powers also are characterised as exclusive some, of which public health is an example, have in practice become concurrent, in the sense of being shared. ${ }^{3}$ These and other similar features of the framework for the federal distribution of powers inevitably shaped the specific form that intergovernmental relations took in the various federations.

The particular distribution of powers also mattered, inevitably. In most federations, the wide range of powers relevant to responding to the pandemic were distributed between two or, in some cases, three levels of government, providing the stimulus for intergovernmental relations with which this chapter deals. The precise formulation and mix of powers affected the dynamics, however. Federations in which significant relevant powers were vested in the federated units, such as Canada, operated differently to those in which a preponderance of power was exercisable by the centre, de jure, as in Austria, or de facto, as in Nigeria. In the context of the pandemic, moreover, the distribution of power to deal with emergencies was an additional consideration. In some federations, power to declare and respond to an emergency is conferred on the centre, directly or indirectly, expanding central power vis-à-vis the federated units, as occurred in Spain and Switzerland. In other federations, including Canada and the US, emergency power is distributed between the levels of government, requiring intergovernmental relations of some kind if coordinating action is required. 
A final set of contextual factors involves federal culture rather than the technical requirements of the federal division of powers. Considerations of this kind are more abstract, but no less relevant to intergovernmental relations. Some have a foothold in the relevant constitution, where they may play a reflexive role in shaping culture (Frankenberg 2006). Certain federations, including Belgium, Italy, and Switzerland, expressly or implicitly prescribe a principle of loyalty or good faith which, in the context of the pandemic, had implications for cooperation and consultation, even if these played out in different ways. The European Union expressly acknowledges a principle of subsidiarity, which can affect the design of intergovernmental arrangements, generally and in application to the pandemic. The Constitution of South Africa prescribes principles for 'cooperative government', now given legislative shape in the Intergovernmental Relations Framework Act of 2005, which require, for example, coordination, consultation, mutual support, and good faith, all of which are relevant to the conduct of intergovernmental relations. The goals of intergovernmental relations are likely also to be affected by expectations in some federations about the equivalence of social conditions, expectations which have no counterpart in others. In Germany, for example, these have a foundation in article 72 of the Basic Law.

\subsection{Purposes}

In many, perhaps most, federations, the initial governmental response to Covid19 came from individual constituent units, or even local authorities, when the virus began to pose a threat. Typically, the core public health and police powers necessary to combat the virus were located in any event at the subnational level. Some of these early, localised actions were well targeted and effective, anticipating strategies that ultimately would be adopted elsewhere. Early steps taken by the Indian states, with Kerala the standout example, involved a range of measures to prevent and track spread of the virus and illustrate the point.

As the virus spread, and the scale of the crisis became apparent, central governments intervened. In some cases, of which India again is an example, the intervention was comprehensive and top-down, severely restricting local discretion; in at least one other, the US, central involvement was limited and spasmodic to the extent that it existed at all. Most federations operated on a spectrum between these two extremes, varying their approach over the course of the year in the light of experience. Whatever approach was adopted, however, at whatever point in time, intergovernmental relations played a role of some kind once both levels of government were engaged.

The value of intergovernmental relations is often assumed, without there being a critical examination of the contribution it makes to multilevel government. Reliance on intergovernmental relations in federations across the world to deal with the complex challenges presented by Covid-19 offers a rare opportunity for such an examination in a practical context. This section considers the 
purposes for which intergovernmental relations were used during this period, as a means of better understanding their potential and their limits.

A familiar purpose of intergovernmental relations, also on display in the context of Covid-19, is 'coordination'. Coordination is too general a term for present purposes, however. It can be focused by asking what was coordinated, between whom and to what degree. In the collective experience of these federations, the subject matter of coordination ranged from the overall strategy for managing the pandemic, as it stood at one point in time to another, to particular aspects of it. The former typically encompassed where and how the balance was to be struck between limiting transmission and preserving the economy - an example might be the length and extent of a particular lockdown. In either case, the function of coordination sometimes was to harmonise different powers and capacities, whether legislative or administrative, across the levels of government, so as to secure an adequately holistic response. Alternatively, coordination served to harmonise the exercise of the same powers by the constituent units in the interests of meeting expected standards of equivalence or, sometimes, to enhance the simplicity of messaging. It follows that coordination was sometimes vertical, involving all levels of government, and sometimes horizontal, involving all or some of the constituent units. Even where a working relationship between the centre and the constituent units was undeveloped or ineffective, as in the US or Brazil, coordination between units in the same region or sharing a similar ideology was a common feature of intergovernmental relations in responding to the pandemic.

The extent or degree of coordination sought varied significantly between federations, ranging from uniformity at one extreme, through various forms of harmonisation, to what in Canada was described as a 'guidance framework', on the other. These choices were driven partly by the opportunities that were presented by the scope of the authority of the respective levels of government, de jure or de facto. In addition, however, they were driven by considerations of what was necessary for an effective response to the pandemic, an assessment that sometimes changed over the course of the year in the light of experience. Spain offers an instructive example for this purpose, although it was not the only one. The constitutional 'state of alarm' triggered by the Spanish government early in the year centralised power and resulted in a top-down approach to management of the pandemic during the first wave of infections, which exposed the limitations of what the centre could do effectively. When the second wave emerged later in the year, a state of alarm was again declared, but this time with the support of the autonomous communities and in a fashion that married coordination with significant decentralisation.

This example makes a broader point. Whatever degree of coordination was sought in response to the pandemic, in most federations some scope was left or taken for a level of local management in a form that assumed local diversity. Where this occurred, its potential advantages were to enable constituent units to respond to local conditions, to experiment with new approaches to a novel problem, and to strengthen accountability to local communities. This potential 
was not realised where local capability was weak, as in South Africa. In some federations, including Ethiopia and Nigeria, limited opportunity combined with low capability also resulted in considerable asymmetry in the extent of local initiative that was taken. Otherwise, however, while the scope for more localised diversity as an element of coordination varied significantly across federations, it was sufficiently prevalent to challenge the automatic equation of coordination with uniformity, at least in tackling problems of this kind.

A second, related purpose of intergovernmental relations during the pandemic was to provide a framework within which consultation might take place between jurisdictions and across levels of government. Notoriously, consultation can take different forms, which in the current context might range from some opportunity for feedback on a predetermined course of action to active engagement enabling perspectives to be shared as a basis for deciding on the action to be taken. The flow of information between jurisdictions in the course of the pandemic was patchy between federations. Even top-down communication was poor in some cases, causing unnecessary confusion: the failure of the government of India to communicate with the states before imposing the nationwide lockdown in March 2020 was an example. In other cases, too, consultation was perfunctory, to the extent that it existed at all. Criticism along these lines was made in regard to South Africa, Mexico, and Argentina, for example.

Nevertheless, there was sufficient use of active, multilateral communication to demonstrate its usefulness for responding to the pandemic and to suggest that it constitutes a significant purpose for intergovernmental relations, hard though it sometimes may be to achieve. At its best, in the course of the pandemic it enabled knowledge about local conditions to be fed into a federation-wide planning process; contributed to the dissemination of innovative ideas and good practice; and underpinned local ownership of intergovernmental solutions. Australia, Switzerland, and Spain provide examples. In some federations, consultation of this kind may be considered to be mandated by requirements of interjurisdictional loyalty. Equally significantly, however, in the context of the pandemic it was driven by the need to maximise the effectiveness of the governmental response.

Other purposes of intergovernmental relations that were revealed by responses to the pandemic can be dealt with more briefly but are equally significant. In some cases, intergovernmental relations were used to solve a shared problem. The arrangements between neighbouring states in Australia to create a 'bubble' to protect border communities from differential lockdowns and border closures are an example; the 'Atlantic bubble' in Canada is another. In other cases, intergovernmental arrangements involved the sharing of resources. The use of defence force personnel to monitor aspects of pandemic control in Canada is an example; the movement of scarce health equipment between states in the US, as needs rose and fell, is another. Another familiar purpose of intergovernmental relations during the pandemic was to achieve economies of scale or other economic benefits that flow from joint, usually central, action. Thus in many federations, 
response to the pandemic involved central procurement of, for example, personal protective equipment, intensive-care beds and vaccine supplies for distribution to the constituent units. Insofar as these supplies were sourced internationally, procurement by the centre was indicated as well.

It is sometimes suggested that a purpose of intergovernmental relations in federations is to manage disputes, particularly in the form of legal action between jurisdictions (South Africa, Constitution, section 41(1)(h)(vi)). Intergovernmental relations can be assumed to have played some role in this regard during the pandemic by providing a framework for joint action to deal with a shared problem, albeit that the speed with which the various crises developed may have inhibited interjurisdictional litigation as well. Disputes resulting in litigation nevertheless occurred, and might have been averted by more effective intergovernmental relations, even though many were instigated by private parties in federations where such procedures are available (Aroney and Kincaid 2017). This chapter on Argentina gives several examples of litigation over competition between provinces in the purchase of respirators and over the movement of medical personnel working in one province but living in another. In other federations, there were legal disputes over constitutional powers and responsibilities. Examples include India and Spain, where questions about the federal division of power were resolved by courts in favour of the centre and Brazil, where challenges to federal action were resolved in favour of the states. Judicial decisions of these kinds affected the dynamic of intergovernmental relations and, indirectly, altered the response to the pandemic.

Finally, intergovernmental relations were used in most federations to alleviate the financial pressures on governments created by the pandemic due to the collapse of economic activity and tax bases and the heightening of expenditure demands. While these effects were felt at all levels of government, the generally superior financial position of the centre typically meant that subnational governments were more exposed. The full magnitude of the economic consequences of the pandemic are yet to be realised, and may call ultimately for a more radical adjustment of existing federal fiscal arrangements. The point made here, however, is that extreme fiscal pressures in some federations, of which Brazil, Nigeria, and the United Kingdom (UK) are only some examples, were mitigated in the shortterm in the course of the pandemic by forms of intergovernmental relations.

\subsection{Modalities}

Comparative studies of intergovernmental relations in federal-type systems across the world show that, at a level of generality, broadly similar types of arrangements, or modalities, are used (Poirier et al. 2015). They include legislative schemes of various kinds designed to achieve a desired level of coordination; meetings of political and other representatives of participating jurisdictions; agreements between jurisdictions, as a framework for future action; joint or shared institutions; and fiscal transfers (Poirier and Saunders 2015). 
The actual design of institutions within each of these categories varies between federations, often significantly, depending on context. So does their scope. In federal experience, for example, intergovernmental arrangements may operate horizontally, vertically, or both; may involve bilateral or multilateral relations; and may include any two or more levels of government. Practice also varies in terms of the legal authority for intergovernmental arrangements. Some arrangements have a framework in the constitution or legislation, or both. South Africa offers a still relatively rare example of constitutional provision for intergovernmental relations that purport to be comprehensive (South Africa, Constitution, Chapter 3), but many constitutions make provision for particular intergovernmental institutions or practices. The Inter-State Council in India (India, Constitution, article 263), the procedure for intergovernmental agreements in Austria (Austria, Constitution, article 15(a)), and the requirement for loyal cooperation in Italy (Italy, Constitution, article 120) are examples. The jury is still out on whether the formalisation of intergovernmental relations enhances their effectiveness, although in principle it has advantages for transparency. Whether a legal framework exists or not, less formalised interaction between jurisdictions is a feature of almost all federations and is critical to understanding their operation in practice.

This section examines the modalities of intergovernmental relations used in the country case studies in dealing with the pandemic. It adopts the same broad categorisation of intergovernmental arrangements used in earlier studies, noting, however, that some intergovernmental practices during the pandemic also departed from previous experience in ways that may have legacies for the future. Where this occurred, it seems to be due to the nature of the challenges presented by the pandemic itself: a fast-moving, inadequately understood, dire threat to the lives and well-being of entire populations, demanding speedy and effective responses from governments. Whether this diagnosis is correct or not, the account that follows shows that some apparently established intergovernmental institutions were bypassed or modified and that some replaced altogether. It also sheds light on practices that worked or not and that offer indication of directions for future change.

Legislative schemes of various kinds typically frame and support intergovernmental action when an enforceable, normative base is required (Poirier and Saunders 2015: 455-57). Legislation also played a role in intergovernmental responses to Covid-19. In emergency conditions in which legislatures often were bypassed, however, many rules were laid down in subordinate rather than primary legislation or, sometimes, executive decrees, to the extent that constitutional systems allowed. Resort to 'guidance' rather than law was another, marked phenomenon in the response of many governments to Covid-19, one which also surfaced occasionally in intergovernmental arrangements. Thus in Canada, for example, 'guidance frameworks' were issued by the federal government, sometimes covering issues such as schools that are within provincial jurisdiction, but without the binding quality that would attract constitutional limitations. 
One common use of legislation to coordinate the actions of jurisdictions during Covid-19 involved the enactment of primary legislation by the federal legislature as an umbrella for action by the constituent units and, sometimes, local government. In some cases, of which Austria and Mexico are examples, the ordinary competences of the federal legislature were sufficient to support this action; in others, including Spain, Switzerland, and Italy, federal competences were expanded by the emergency conditions. In some federations, some or all the constituent units supported federal leadership, actively or passively, even when the limits of federal competence were doubtful; others were critical of overcentralisation. In a distinctive example of support for central legislative action, the devolved legislatures of the UK gave consent to the enactment of the Coronavirus Act of 2020 by the Westminster Parliament in the form required by the 'Sewel' Convention (Institute for Government 2020).

The bases on which central legislation engaged the constituent units varied. In some cases, as in Germany, Switzerland, or South Africa, the constituent units were engaged through the usual process of implementing federal legislation. In others, including Mexico, Brazil, and Ethiopia, the constitutional scheme permitted the federal legislature to enact what in essence was framework legislation, within which constituent units could, or had to, act. In others, again, of which Russia and India were examples, the federal legislation was prescriptive, providing rules with which constituent units had to comply or mandating the action they were to take.

Whatever the legal basis for this form of joint action, key points of difference between federations in practice concerned the extent to which constituent units had discretion in applying and supplementing the federal law in local conditions; the extent to which units were consulted in relation to the form of the federal law and the action permitted or required to be taken under it; and whether units were accountable for their actions to their own communities or to the federal government. The spectrum ranged from Germany, where the Länder implemented federal legislation in their own right under article 83 of the Basic Law, had considerable discretion in doing so, and were consulted through the institution of the Bundesrat in addition to other means, to India, where the states acted within the boundaries of unilateral Union legislation on which they were not consulted at all. In the case of some federations, the scope of authority exercisable by constituent units expanded in the course of the year, as experience suggested that there was likely to be benefit in relying on rules and processes of administration that were locally informed and could be adapted to local conditions. Spain was a notable case in point, moving from centralised control under the first state of alarm to a form of 'co-governance' during the second.

More dualist federations typically do not involve the constituent units in the implementation of regular federal legislation. Where legislation is used for intergovernmental arrangements, the goal instead is to ensure that the legislation for which each jurisdiction is responsible is harmonised appropriately with that of all the others. Time did not permit the negotiation and implementation of elaborate 
legislative schemes of this kind during the pandemic. The technique was used nevertheless in several ways in Australia and, to a lesser extent, in Canada and the US.

Any agreement on coordination, whether vertical or horizontal, relied on voluntary compliance by the parties, through legislation, including delegated legislation, where necessary. Decisions of the 'National Cabinet' in Australia, for example, were given effect in that way, as was coordinated action between neighbouring constituent units in Canada and the US. Furthermore, in some cases, of which Australia again is an example, strategies or 'plans' for identifying the roles of the different levels of government in dealing with disasters generally and pandemics in particular had been developed in earlier years and had prompted implementing legislation that was coordinated to this extent. The use of plans is considered further below in the context of intergovernmental agreements. They could not have been expected to anticipate all the exigencies presented by the realities of the pandemic, but they offered at least a starting point.

Some of the practical difficulties of coordinating government action under the legislation of different jurisdictions are illustrated by an Australian controversy early in the pandemic. The critical issue was uncertainty about whether officers of the federal government or of New South Wales had been responsible for allowing infected passengers returning from an international cruise to enter New South Wales and travel to other parts of Australia. An official inquiry concluded that the responsibility lay with New South Wales, but neither level of government emerged from the Inquiry unscathed. The Commissioner recommended that both bureaucracies develop 'better levels of awareness of their own and each other's roles and responsibilities ... and more formal protocols for ... interaction and communication' (Special Commission of Inquiry 2020: 2.20).

A second core institution of relations between government comprises interjurisdictional forums of various kinds that involve two or more participating jurisdictions, whether operating vertically or horizontally (Poirier and Saunders 2015: 458-63). The most high-profile of such forums involve heads of government or line ministers, but many others involve bureaucrats at different levels or officeholders of various kinds across participating jurisdictions. This section focuses on intergovernmental forums involving political actors, while also noting the practical contribution of others in responding to the pandemic, some of which, including, for example, the Pan-Canadian Public Health Network, are identified in the case study chapters.

In some federations, a forum for political collaboration between jurisdictions is built into the central law-making process. The German Bundesrat is a prime example, but second chambers in other jurisdictions, including South Africa, are constituted so as to represent the constituent units and have some, if varying, potential to act in this way. Whether or not a federation has a second legislative chamber or equivalent that can contribute to effective coordination, other forums also may be used for the purpose that are more self-evidently intergovernmental in design. When the pandemic broke out, some federations had 
well-established intergovernmental forums through which political leaders could meet should they choose to do so. Examples include Australia, where a complex network of ministerial councils, with the Council of Australian Governments (COAG) at the apex, had existed since 1992; South Africa, where a President's Co-ordinating Council (PCC) and supporting councils of line ministers were established by legislation in 2005, implementing Chapter 3 of the Constitution; India, where an Inter-State Council (ISC) was established in 1990 by presidential order under article 263 of the Constitution; Switzerland, where a system of largely horizontal inter-cantonal conferences was complemented from 1993 by a Conference of Cantonal Governments (Schnabel and Mueller 2017); and Spain, where a Premiers' Conference was established by the central government in 2004.

One of the more interesting observations from the collective experience of federations during the pandemic was how much of the intergovernmental status quo was found wanting in the face of this sudden and novel threat. This was not the case everywhere. In Germany, for example, less formal meetings between the Chancellor and the first ministers supplemented the limitations of the Bundesrat to coordinate the actions of governments in an area where so much authority lay with the Länder and seem to have been adequate to the purpose. In other federations, existing arrangements proved less satisfactory in a variety of distinct ways.

Federations where intergovernmental forums were already weak or nonexistent, as in Mexico, had no obvious vehicle to bring heads of government together, prompting calls for better intergovernmental architecture in the future. In Mexico, ad hoc arrangements were made for a meeting, but not until August, when the pandemic was well advanced. In Ethiopia, where such forums also were lacking, coordination took place through party connections, to the extent that it took place at all. In others, including the US, Brazil and Nigeria, horizontal meetings achieved some coordination to fill the gap partly, but typically these were not fully inclusive, bringing together governors connected by region or, sometimes, party affiliation.

More surprisingly perhaps, many federations in which intergovernmental forums were available altered them or did not use them at all. In some cases, they were bypassed in favour of bodies designed to coordinate action at the centre, initially with no constituent unit representation at all. Argentina, Italy, and Nigeria are examples. Relevantly for present purposes, however, in at least some cases, including Italy, intergovernmental forums were activated or reactivated in the course of the year in the light of experience with the pandemic. In a similar vein, in some cases, of which the UK and Belgium are examples, central coordinating bodies were supplemented, permanently or on an occasional basis, by representatives of the constituent units. Along the same lines again but in an example of a different kind, in India, while the formal intergovernmental forum, the Inter-State Council, did not meet, eight less formal online meetings are reported to have occurred between the Prime Minister and the state premiers in the period covered by this chapter in this study. 
In some federations, experience with the pandemic proved a catalyst for change to intergovernmental forums. One phenomenon reported across several federations is that intergovernmental forums, when they operated at all, did so from the top-down, in a demonstration of central leadership and control. In varying ways, this seems to have occurred in, for example, Spain, Austria, Switzerland, and South Africa. In the first three of these cases, the extent of central leadership was accepted as a viable way to respond to the pandemic in that particular context. In Spain, however, top-down control by the centre through the Premiers' Conference during the first phase of the pandemic subsequently changed to the much more interactive approach of 'co-governance', during which the Premiers' Conference met 16 times, offering a model that may also be relevant for the future.

More dramatically still, in Australia, COAG, the existing forum for heads of government, was replaced early in the pandemic by a new, intergovernmental 'National Cabinet', designed to operate quickly, efficiently and with minimal bureaucracy. The Australian approach had the advantage of recognising the distinct roles of each of the participating governments and leaving considerable discretion to each. This new intergovernmental architecture was developed speedily and to meet a single purpose, however. It remains to be seen whether it will survive into a post-pandemic era as the vehicle for coordination across a broad spectrum of intergovernmental action.

A third, more amorphous, category of institutions comprises boards and agencies of various kinds that serve an intergovernmental purpose (Poirier and Saunders 2015: 467-9). Typically, these have specialist qualifications and operate at a degree of arms-length from government. Their primary function may be advisory or regulatory, and they may be established or constituted by participating jurisdictions collectively or by one level of government alone, usually the centre.

In the context of the pandemic, most such bodies were health-related, although some were mandated to deal with responses to emergencies more generally, or to advise on the economic fallout of the pandemic. Their functions ranged from providing high-level epidemiological and related health advice, to the development, coordination, and monitoring of the implementation of plans to manage the crisis by, for example, limiting community transmission. The mixture of specialist health and bureaucratic expertise required was met in some cases through reliance on multiple bodies and, in others, through the composition of a single agency or body. Given the involvement of all levels of government in responding to the pandemic, one challenge was to ensure that relevant specialist expertise was available to each level of government; another was to coordinate the reactions of each jurisdiction to the specialist advice they received.

The complexity of these arrangements, many of which also evolved over time, makes generalisation difficult. They can be seen, however, as falling into three, sometimes overlapping, categories. In some cases, the agency was established at and responsible to the national level of government, affecting action at other levels of government either through direction or through interaction between 
agencies organised in an essentially hierarchical structure. The Brazilian National Health Regulator and the Nigerian National Emergency Management Agency are examples of the former, while the Indian Disaster Management Authorities are an example of the latter. In a second category of cases, the agency has intergovernmental elements in its composition. The Austrian commission that published risk assessments for the coronavirus 'traffic light system' is an example, comprising experts, civil servants, and Land representatives. The Epidemics Task Force in Switzerland might also be placed in this category.

In what might be considered a third category, both the centre and the constituent units maintained specialist agencies of their own between which communication took place. Australia and Canada, at least, took this approach. In Australia, each jurisdiction had a chief health officer to advise the government and, sometimes, exercise statutory power. These officers communicated informally with each other, however, and met regularly in an intergovernmental forum, the Australian Health Protection Principal Committee (AHPPC), which in turn advised the 'National Cabinet'. In an era of suspicion of experts, it is an interesting question whether, as an aspect of multilevel government, the multiple sources of official expertise on which some federations relied during the pandemic strengthened trust in the decisions that were made or complicated matters further.

Agreements between participating jurisdictions are a familiar mechanism in intergovernmental relations, recording decisions about collective action to achieve particular outcomes or resolve particular problems (Poirier and Saunders 2015: 469-74). The incidence of intergovernmental agreements varies between federal-type systems depending on context, including in this instance the legal and political system. Some agreements require legislative consent, while others are made entirely through executive power. Some agreements are legally enforceable; others have, at best, the status of soft law.

At first glance, intergovernmental agreements played a relatively minor role in federations in responding to the pandemic in 2020. To the extent to which this is so, it may reflect the speed at which the pandemic spread, which required a government response that had no time for the lengthy negotiations between jurisdictions that agreements may require. On closer inspection, however, agreements were a feature of intergovernmental relations during the pandemic as well, even if they were not negotiated for the purpose or, in some cases, referred to in those terms.

In the first place, the complexities of hospitals and health care in federations are such that there often are general agreements dealing with such matters, necessarily affecting the use of hospitals during the pandemic. The account of developments in Austria draws attention to the long-standing significance of health-care agreements under article 15(a) of the Austrian Constitution, but agreements of this kind exist elsewhere as well. Secondly, in a point that may be more specific to experience with the pandemic, in many federations the intergovernmental response was described as being framed by pre-existing 'plans' or equivalent terms. Thus, for example, in Canada there was a Federal/Provincial/ 
Territorial Response Plan for Biological Events, in addition to a range of supplementary intergovernmental instruments; in Nigeria, there was a Pandemic Multi-Sectoral Response Plan; in the UK, a Coronavirus Action Plan; in Russia, a Corona Crisis Action Plan; in Spain, a National Early Warning and Rapid Response System; and in Australia, an Australian Health Management Plan for Pandemic Influenza, a National Strategy for Disaster Resilience and an Emergency Response Plan for the Covid-19 Pandemic, among others.

Several questions arise, not all of which can be answered with information presently available. It is clear that not all 'plans' that were put to use during the pandemic were intergovernmental in any relevant sense. In the examples above, both the Spanish 'System' and the Nigerian Plan seem to have been developed by the central government alone and so fall into this category. It is equally clear, however, that in some cases a plan is the equivalent of an intergovernmental agreement. This point is made specifically in the Canadian chapter, but it seems to reflect the understanding in other federations as well, including the UK. These circumstances prompt a question about what it is in relation to the manner in which the plan was developed, or its content, that causes the terminology of 'plan' to be used in lieu of a descriptor that signifies collective agreement more obviously.

In yet another group of federations in which plans played a role during the pandemic, the 'plan' had an intergovernmental element of some kind. The Russian plan, for example, is said to have been adopted by all the constituent units; the Australian 'Strategy' was officially developed through COAG, as the intergovernmental predecessor of what now is the National Cabinet. In these and other cases, however, there are questions about the extent to which the arrangements were informed by consultation with the constituent units and were consensual, at least in the sense signified by signature to an agreement. Insofar as many of these plans and other arrangements were laid down in advance with a view to managing future emergencies, there is another question about the extent to which they were adequate to the purpose as this particular emergency evolved. This issue is flagged most specifically in relation to Canada but, again, seems likely also to be relevant elsewhere. The difficulty of finding answers points to problems with transparency, to which the following section of this chapter refers.

One final set of intergovernmental mechanisms that require brief mention concern fiscal arrangements (Poirier and Saunders 2015: 474-6). The techniques themselves are familiar: fiscal transfers between levels of government, tax-sharing arrangements, and support for borrowing of various kinds. The fiscal dislocation caused by the pandemic through substantial additional expenditures and loss of tax and other revenues as economic activity slowed or stopped, made it inevitable that mechanisms of this kind would be a component of intergovernmental relations. More action can be expected on this front as the economic consequences of the pandemic become clearer over time.

In the short term, however, the chapters in this book record the use of transfers to assist constituent units either generally or in relation to pandemic-related 
expenses in, for example, Brazil, Nigeria, India, Russia, and Ethiopia; a renegotiation of the Barnett formula for revenue redistribution in the UK; assistance with the debts of constituent units in Brazil, Russia, and Nigeria; and the use of fiscal transfers in Germany not only to supplement Länder revenues but also to induce Länder compliance with a coordinated policy approach to aspects of pandemic management. There are indications in this chapter of longer-term implications of experience with the pandemic for intergovernmental fiscal relations. One, to which the Swiss chapter refers, is the impact of the Covid-19 experience on the viability of the continued use of the fiscal equivalence principle under article 43(a)(3) and (4) of the Swiss Constitution.

\subsection{Insights}

Intergovernmental relations were a feature of the response of all federations to the emergencies created by the pandemic. The ways in which intergovernmental relations were used varied, however, not only in the mechanisms employed but in the proportionate contribution of the centre and the constituent units, including, in many cases, local governments. In some federations, among them, for example, Mexico, Nigeria, South Africa, India, Austria, and Russia, the centre dominated decision-making over the period covered by this chapter, once the scale of the problem had become evident. In others, of which the US, Canada, and Australia are somewhat different examples, the approach was more dualistic, whilst nevertheless involving some interaction between governments. The experiences of the remainder lie between these two poles, striking a balance in a variety of ways.

Each federation ultimately will assess its own performance in response to Covid-19, including the adequacy of interactions between governments. On the evidence of the chapters in this book, some, including Germany and Canada, are broadly satisfied with the workings of intergovernmental relations, at least up to the end of 2020. In some cases, of which Spain and Australia are examples, the experience of dealing with the pandemic itself caused shifts in the conduct of intergovernmental relations the durability of which remain to be seen but which seem to have met with broad approval in the short term. In other cases, the chapters suggest either that the jury is still out on the effectiveness of intergovernmental relations or that reform is indicated. In most of the cases in this latter category, including Brazil, Argentina, and the UK, the primary concern is over-centralisation. An overlapping concern, also in Mexico, is patchy and dysfunctional intergovernmental relations. In the US, the primary concern instead was a shortfall in leadership from the centre that exacerbated the problems of a dualist approach lacking the possibility of productive vertical interaction even when it patently was needed.

Despite the diversity of usage of intergovernmental relations during the pandemic, some insights are suggested by the collective experience. One is that, to maximise the potential of a federation for responding to crises such as those 
presented by Covid-19, intergovernmental relations cannot be overly top-down. Central leadership is useful and may be necessary, but it should be understood as central leadership in a federation, in which the active contribution of constituent units contributes to informed and legitimate intergovernmental decisions and serves a variety of purposes.

This is not news in federations with a developed federal culture. Switzerland is such an example, where consultation with the cantons is prescribed by the Constitution and underpinned by the political process (Switzerland, Constitution, article 45 and 55). In other federations, such principles are undeveloped or imperfectly realised. In Canada and Australia, for example, the nearest equivalent is a principle of 'cooperation', which has evolved as a tool for understanding the scope of the legislative powers of the respective levels of government rather than as a standard for the manner of their collective exercise (Gaudreault-DesBiens and Poirier 2017). In Italy, central consultation and cooperation with the regions in the initial phase of the pandemic were described as 'half-hearted' despite a principle of loyal cooperation in article 120(2) of the Constitution - neither level of government appears to have adopted it adequately. Grappling with the pandemic changed principles of this kind from abstract goals to practical necessities in ways that offer new insight into what intergovernmental relations require.

A second, but related, insight is that the goal of effective intergovernmental relations is not necessarily uniformity. Some of the case studies, including Canada, Australia, and Germany, show approaches to intergovernmental relations that assumed significant diversity in policy and practice at the subnational level, for which subnational governments were accountable to their own institutions and voters. In many other cases, including Spain, Italy, and Russia, initial assumptions about the need for uniformity gave way over time to increasing diversity at the subnational level, as experience with the pandemic showed that local discretion, responding to local conditions, could be advantageous. Less charitable explanations, about distributing blame, are possible too, but the trend is notable, nevertheless. The extent to which divergent policies and practices were useful and acceptable at the level of constituent units varied with context, including the degree of actual difference in conditions on the ground and the strength of adherence to principles of equivalence in regulatory standards. The demonstration of the broader roles that intergovernmental relations can play without prioritising centralisation and uniformity is another useful outcome of the experiences of 2020 all the same.

Thirdly, the real demands that the pandemic placed on governments at all levels highlighted the importance of capacity, in the sense of capability. The capacity of the several levels of government to perform the roles assigned to them is a sine qua non of a working federation. Too often, however, the significance of capacity, particularly of the subnational levels of government, is ignored or imperfectly understood, papered over by centralisation, including through intergovernmental relations. This becomes less possible when intergovernmental arrangements require an active contribution from constituent units. 
The challenges presented by lack of capacity at subnational levels of government in responding to the pandemic were experienced in many federations, including South Africa, Nigeria, and Italy. The lesson for the future is not only to design intergovernmental arrangements in ways that take capacity into account but also to work to build capacity, such that all levels of government can make contributions that realise the potential of intergovernmental relations.

One final concluding observation concerns transparency and accountability, notoriously victims of intergovernmental relations. The extent of the problem differs between federations. Transparency and accountability are less affected where, for example, there is a legal or constitutional framework for intergovernmental relations or a requirement for certain types of arrangements to be approved by legislation, if only because, in either case, aspects or relations between governments have greater public exposure. Almost by definition, however, intergovernmental relations typically rely to a considerable extent on meetings, agreements, and actions of other kinds in which the primary actors are members of the executive branch, interacting in relatively unstructured settings and operating in confidence.

Problems of transparency and accountability in intergovernmental relations were in evidence during the pandemic as well. Ironically, to the extent that each level of government had discrete roles for which they were accountable to their own voters; in some federations, there was a higher level of public understanding of and interest in who was doing what than often is the case. In other respects, however, familiar problems recurred, exacerbated by the need for speed in responding to the pandemic as it unfolded and, in many jurisdictions, even less parliamentary scrutiny than usual.

Two examples may be given. One is uncertainty about how and on what bases roles and responsibilities for dealing with the pandemic were allocated between governments. The Canadian chapter specifically queries whether the intergovernmental arrangements in the Response Plan were 'actually mobilised', but similar issues almost certainly have arisen elsewhere. The second example concerns the various intergovernmental forums through which the bulk of intergovernmental relations occurred. Problems of accountability inevitably arise in relation to collective decisions of an intergovernmental body, the individual members of which are politically accountable to different institutions and different constituencies. These problems are greater if there is lack of transparency about the operating rules for such bodies, the influences that are brought to bear in the course of decision-making, and the decisions that are eventually made matters in which practice differs between federations.

An Australian example, admittedly extreme, shows how such problems arise. The operating rules for the new apex intergovernmental forum, the National Cabinet, which was established early in 2020, have never been publicly explained. Decisions are announced briefly, by 'media statement', in terms that are predictably general and opaque. Furthermore, in a complete break from earlier practice, the 'National Cabinet' is institutionally located under the umbrella of the 
Commonwealth Cabinet, apparently in order to attract the same rules about solidarity and confidentiality, including protection from freedom of information legislation (Department of the Prime Minister and Cabinet 2020). Legal challenges to this arrangement can be expected. In the meantime, however, it stands as a reminder that designing intergovernmental arrangements in ways that adequately meet democratic standards for transparency and accountability remains a work in progress.

\section{Notes}

1 The power in question deals with 'quarantine' (s 51(xi)). Section 8 of the Biosecurity Act of 2015 (Cth), which exercises the power, includes a standard disclaimer of intention to limit a state law 'capable of operating concurrently' with the Commonwealth law.

2 The Mexican chapter refers to 'coordination' (in the field of civil protection) as involving 'the creation of mechanisms of coordination and collaboration among orders of government in a specific policy area', noting, however, that the procedure was not used in respect of the pandemic.

3 The point is made by Johanne Poirier, in commenting on an earlier version of this chapter.

\section{References}

Aroney, N. and Kincaid, J. (eds). 2017. Courts in Federal Countries: Federalists or Unitarists? Toronto: University of Toronto Press.

Department of the Prime Minister and Cabinet. 2020. Cabinet Handbook, 14th ed., https:// pmc.gov.au/resource-centre/government/cabinet-handbook (accessed on 1 February 2021).

Frankenberg, G. 2006. 'Comparing Constitutions: Ideas, Ideals, and Ideology - Towards a Layered Narrative', International Journal of Constitutional Law, 4: 439-59.

Gaudreault-DesBiens, J. and Poirier, J. 2017. 'From Dualism to Cooperative Federalism and Back? Evolving and Competing Conceptions of Canadian Federalism', in P. Oliver, P. Macklem and N. Desrosiers (eds), The Oxford Handbook of the Canadian Constitution, pp. 391-413. New York: Oxford University Press.

Institute for Government. 2020. 'Sewel Convention', https://www.instituteforgovernment. org.uk/explainers/sewel-convention (accessed on 1 February 2021).

Poirier,J. and Saunders, C. 2015. 'Conclusion: Comparative Experience of Intergovernmental Relations in Federal Systems', in J. Poirier, C. Saunders and J. Kincaid (eds), Intergovernmental Relations in Federal Systems, pp. 440-95. Canada: Oxford University Press.

Poirier,J., Saunders, C. and Kincaid,J. (eds). 2015. Intergovernmental Relations in Federal Systems. Canada: Oxford University Press.

Saunders, C. and Dziedzic, A. 2017. 'The Meanings of Concurrency', in N. Steytler (ed.), Concurrent Powers in Federal Systems: Meaning, Making, Managing, pp. 12-31. The Hague: Brill/Nijhoff.

Schnabel, J. and Mueller, S. 2017. 'Vertical Influence or Intergovernmental Coordination? The Purpose of Intergovernmental Councils in Switzerland', Regional and Federal Studies, 27(5): 549.

Special Commission of Inquiry. 2020. Report of the Special Commission of Inquiry into the Ruby Princess, New South Wales, https://www.rubyprincessinquiry.nsw.gov.au/report (accessed on 1 February 2021). 